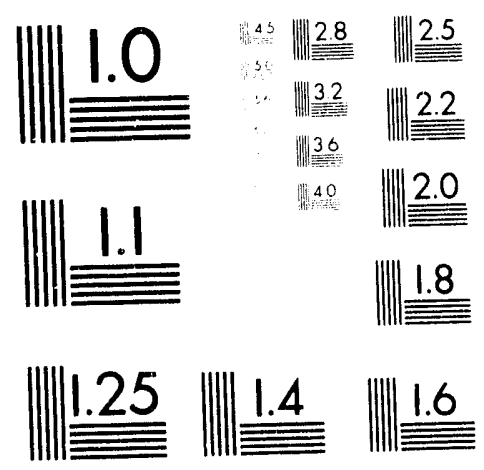



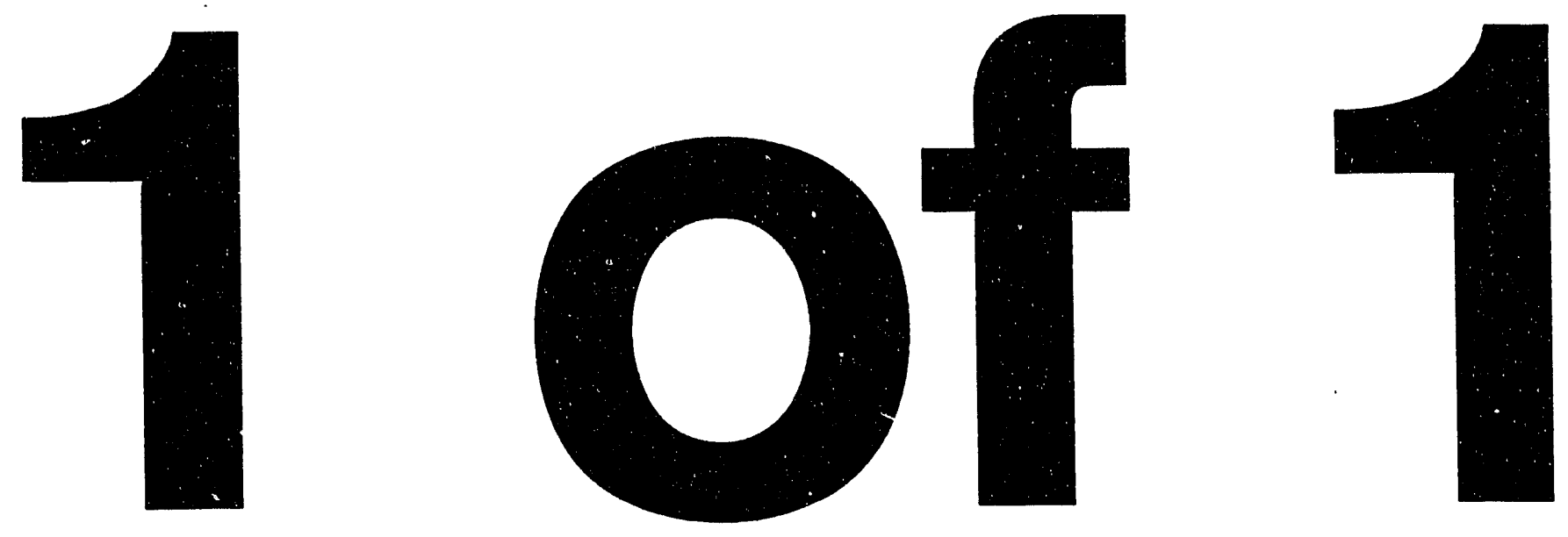


\title{
THE DEVELOPMENT OF AN IN-VESSEL CRYOPUMP SYSTEM FOR THE DIII-D TOKAMAK
}

\author{
by \\ K.M. SCHAUBEL, C.B. BAXI, G.L. CAMPBELL, \\ G.J. LAUGHON, M.A. MAHDAVI, M.M. MENON, \\ C.C. MAKARIOU, J.P. SMITH, M.J. SCHAFFER
}

JULY 1993

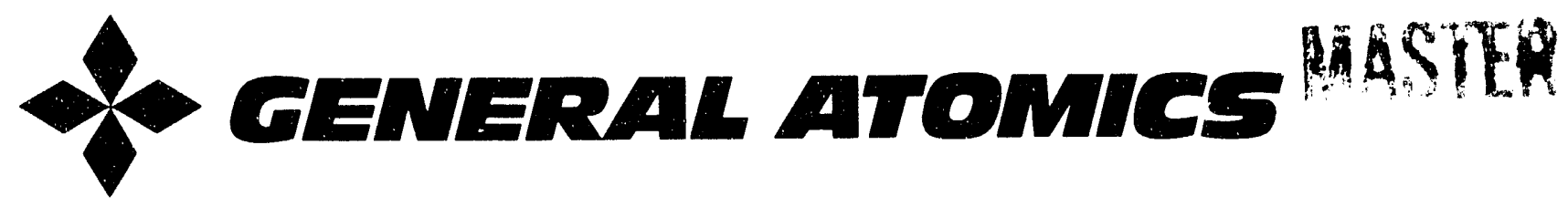




\section{DISCLAIMER}

This report was prepared as an account of work sponsored by an agency of the United States Government. Neither the United States Government nor any agency thereof, nor any of their employees, makes any warranty, express or implied, or assumes any legal liability or responsibility for the accuracy, completeness, or usefulness of any information, apparatus, product, or process disclosed, or represents that its use would not infringe privately owned rights. Reference herein to any specific commercial product, process, or service by trade name, trademark, manufacturer, or otherwise, does not necessarily constitute or imply its endorsement, recommendation, or favoring by the United States Government or any agency thereof. The views and opinions of authors expressed herein do not necessarily state or reflect those of the United States Government or any agency thereof. 


\title{
THE DEVELOPMENT OF AN IN-VESSEL CRYOPUMP SYSTEM FOR THE DIII-D TOKAMAK
}

\author{
K.M. Schaubel, C.B. Baxi, G.L. Campbell, G.J. Laughon, M.A. Mahdavi, \\ M.M. Menon, ' C.C. Makariou, J.P. Smith, M.J. Schaffer \\ General Atomics \\ San Diego, CA, 92186 \\ IOak Ridge National Laboratory
}

\begin{abstract}
The design, testing and initial operation of the DIII-D advanced divertor cryocondensation pumping system is presented. The pump resides inside the tokamak plasma containment vessel where it provides particle exhaust pumping, and it is subjected to Joule heating and hot particle heat loads during each 10 second discharge. In addition, the pump must withstand plasma disruption induced electromagnetic forces and $400^{\circ} \mathrm{C}$ bake-out temperatures. Cooling is accomplished by forced flow liquid helium with the two-phase helium exhaust passing through a reliquefier for thermal efficiency. A prototype pump was constructed to study surface temperature rise as a function of flow geometry, applied heat load, helium mass flow rate, and pump outlet conditions. Prototype testing led to the development of a special geometry which was demonstrated to enhance two-phase flow stability and overall heat transfer. During initial operation, deuterium pumping speeds of $32.000 \mathrm{~L} / \mathrm{s}$ at $2 \mathrm{mTorr}$ pressure were achieved with a helium flow rate of $5 \mathrm{~g} / \mathrm{s}$. This speed was maintained during $300 \mathrm{~W}, 8 \mathrm{~s}$ long test heat pulses which meets operational goals.
\end{abstract}

\section{INTRODUCTION}

The DIII-D tokamak (Fig. 1) is an experimental fusion device which has been operational at General Atomics since 1986. The tokamak consists of a donut-shaped vacuum vessel with a $D$-shaped cross section, magnetic coils for plasma heating and shaping, auxiliary plasma heating systems, and diagnostic systems. The focus of the DIII-D program is on developing efficient plasma current drive methods and solving the problems of power, particle and impurity control. The goal is to demonstrate reactor relevant heating and current drive in a well confined plasma, using high power microwaves, and show that these conditions can be maintained for at least 10 seconds in order to obtain data for the design of future reactors.

The Advanced Divertor Program was started at DIII-D in 1989 for the purpose of studying; (1) density and impurity control for transport studies and current drive, (2) enhancement of plasma performance, and (3) divertor engineering studies and 


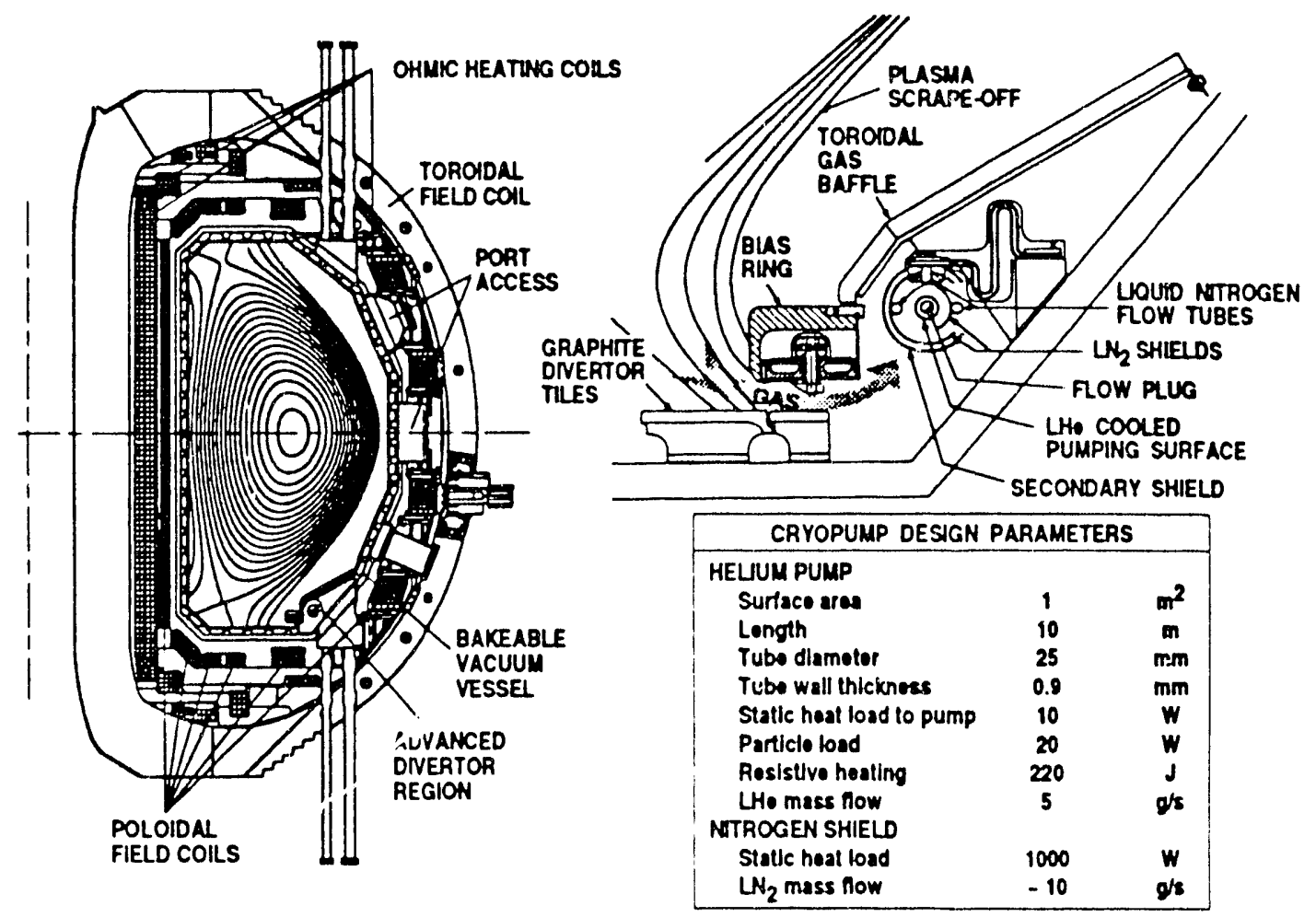

Figure 1. Cross section of the DIII-D tokamak (left) and expanded cross section showing the advanced divertor components (right).

improvements. 1 The advanced divertor configuration (Fig. 1) consists of the graphite divertor floor tiles, an electrically biasable ring electrode, and a pumping plenum formed by a toroidal gas baffle. Adequate gas pressure buildup has been observed in the pumping plenum to allow active cryopumping to be carried out.

A liquid helium cooled cryocondensation pump was installed in the advanced divertor pumping plenum and has been operational since early 1993. The cryopump is located in the space beneath the gas baffle where pressure buildup takes place. Hydrogen or deuterium are pumped by cryocondensation onto the Inconel surface at $4.3 \mathrm{~K}$. The pumping surface has an area of $1 \mathrm{~m}^{2}$ and is cooled by forced flow liquid helium at a pressure of $1.15 \mathrm{bar}$ ( 2 psig). The cryopump is being used for actively pumping exhaust particles from the plasma scrape off layer as they are deflected into the plenum. Plasma density control is accomplished by controlling the position of the scrape off layer strike point in relation to the cryopump. Impurities, which are at a higher density in the scrape off layer, are removed from the plasma by the cryopump.

\section{DESIGN}

\section{In-Vessel System}

The design of the pump was particularly challenging because it resides inside the plasma chamber of the DIII-D tokamak. During normal plasma discharges the surface temperature must remain sufriciently low to maintain pumping while the pump is subjected to Joule heating induced by the tokamak ohmic heating coils as well as energetic particles from the plasma. During plasma disruptions it must withstand mechanical forces caused by large and varying electromagnetic fields. Electrical arcing damage during disruptions is also 
a danger due to voltages which may develop between the pump and the vacuum vessel wall. In addition, the pump must withstand the $400^{\circ} \mathrm{C}$ bakeout temperatures which are achieved routinely during vacuum vessel conditioning. A detailed description of the in-vessel system design can be found in Ref. 2.

The pump consists of a series of concentric Inconel 625 tubes which form a closed toroidally continuous ring. Inconel 625 was chosen over AISI 316 stainless steel because its electrical resistivity is higher by a factor of 2.3 which limits Joule heating in the pump. ${ }^{3}$ Cooling of the pump is accomplished by forced flow two-phase helium with a mass flow of $5 \mathrm{~g} / \mathrm{s}$. The helium pump is formed by a $25 \mathrm{~mm}$ diameter, $10 \mathrm{~m}$ long tube. A $19 \mathrm{~mm}$ diameter porous flow plug is installed to form an annular flow cross section thereby increasing flow velocity and heat transfer. A pair of liquid nitrogen cooled radiation shields provide a line of sight shield for the helium pump. Over a period of time the nitrogen shields can condense a significant amount of water vapor from the tokamak vacuum. Therefore, a secondary shield surrounds the nitrogen shields to prevent water desorption which can occur if energetic particles strike the nitrogen shields (water molecules are detrimental to the plasma). The secondary shield also provides radiation shielding for the nitrogen shield. A series of windows are cut inio the nitrogen and secondary shield tubes to provide a gas conductance patn with occasional continuous webs providing structural strength. Liquid helium flows toroidally with a $360^{\circ}$ single pass through the pump while nitrogen makes a double pass to cool each of the two nitrogen shields. All cryogens are fed from a single vacuum vessel feedthrough port. The secondary shield is at DIII-D vessel potential while the nitrogen shields and the helium pump are electrically isolated from the vessel. The nitrogen shield and helium pump are continuous and electrically connected together only at the feedthrough port which is connected to the vessel through a resistor.

Two cryopump design options were considered in detail; (1) a toroidally continuous ring, and (2) a toroidally segmented pump with electrical gaps at one or more toroidal locations. The segmented pump design has the advantage that no to: $: \mathrm{Hal}$ current is induced by the normal ohmic heating coil current ramping. However, voltage potentials of $300 \mathrm{~V}$ would develop between the pump and the vessel wall during plasma disruptions which could cause electrical arcing (especially in the plasma environment). Arcing could damage the flow tubes and would cause current to flow through the pump thereby creating electromagnetic loads. Option 1 was chosen to lower the voltage potential and avoid arcing. However, the selection of option 1 means that current is induced in the pump before and during every plasma discharge causing electromagnetic loads ${ }^{4}$ and up to $220 \mathrm{~J}$ of heat deposition in the helium pump. A cryogenic testing program (described later in this paper) was carried out to evaluate the role of this heating for various prototype configurations.

\section{Ex-Vessel System}

The advanced divertor cryopump is a subsystem of the overall DIII-D cryosystem. In addition to supporting the advanced divertor cryopump, the DIII-D cryosystem also supplies liquid helium and liquid nitrogen to the four neutral beam injector cryopanels and provides helium liquefaction for the electron cyclotron heating system $(\mathrm{ECH})$ superconducting magnets. A major upgrade of the DIII-D cryosystem was completed in early 1993 to replace the existing high maintenance reciprocating refrigerator and provide the additional capacity required for the advanced divertor cryopump and the planned pellet injector. A detailed description of the DIII-D cryosystem can be found in Ref. 5 .

A simplified flow diagram for the advanced divertor cryosystem is shown in Fig. 2. The flow scheme used is similar to that of the DIII-D neutral beam cryopanels. 6 Liquid helium is pressure fed at $1.43 \mathrm{bar}(6 \mathrm{psig})$ from the main $3800 \mathrm{~L}$ dewar to the cryostat via the distribution box and the $26 \mathrm{~m}$ long, 3-pass Kabelmetal transferline. ${ }^{7}$ Liquid helium entering the cryostat is subcooled and throttled into the cryopump via the cryostat transferline at $5 \mathrm{~g} / \mathrm{s}$ and $1.15 \mathrm{bar}(2 \mathrm{psig})$. The helium enters the cryopanel as nearly $100 \%$ liquid and exhausts as a low quality two-phase mixture after absorbing thermal energy. The two-phase stream then passes through the subcooler and heat exchanger/phase separator where it is fully vaporized and warmed to nearly room temperature before returning to 


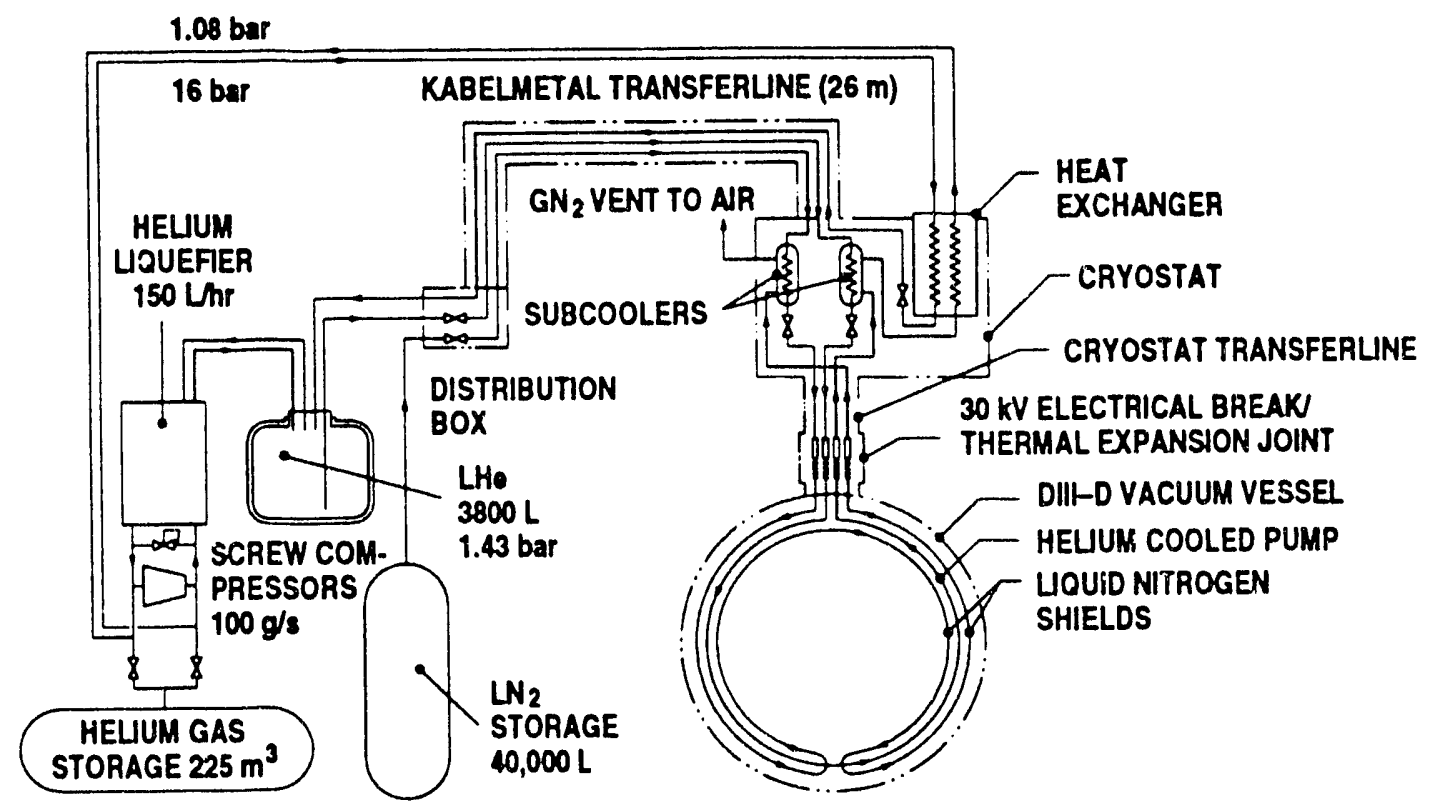

Figure 2. Advanced divertor cryosystem flow diagram (simplified)

compressor suction. High pressure helium gas from the compressor is counterflow cooled through the heat exchanger by the two-phase helium returning from the pump. The cold high pressure stream is then expanded through the Joule-Thomson valve and returned to the 3800 L Dewar via the Kabelmetal transferline. Liquid nitrogen from a 40,000 L bulk storage tank is supplied to the cryostat at 4.12 bar ( 45 psig) via the Kabelmetal transferline.

The cryostat contains 4 cryogenic flow control valves, the J-T valve, the precool piping and valves, the helium and nitrogen subcoolers, the heat exchanger/phase separator, and the temperature and pressure instrumentation. All helium-cooled components within the cryostat are superinsulated and protected by a liquid nitrogen-cooled radiation shield. The $3800 \mathrm{~L}$ supply dewar is $4 \mathrm{~m}$ higher than the cryopump and the high point in the Kabelmetal transferline is $7 \mathrm{~m}$ higher than the cryopump. Therefore, two phase flow instabilities caused by elevation changes and long transferlines were a design concern. To alleviate flow problems, the cryostat is located adjacent to the cryopump feedthrough and at the same elevation. Two phase helium exhausting from the pump is phase separated and vaporized in the heat exchanger before undergoing elevation changes. The two phase J-T stream from the cryostat undergoes the $7 \mathrm{~m}$ elevation change as it passes through the Kabelmetal transferline on its way to the dewar, but flow is stable because it is driven by high pressure. Operation of the advanced divertor cryosystem has shown that this configuration is quite stable.

The cryostat is connected to the cryopump feedthrough port by a $3.5 \mathrm{~m}$ long transferline which is vacuum insulated and liquid nitrogen shielded. The cryostat transferline contains four $12.5 \mathrm{~mm}$ diameter feed tubes (helium and nitrogen; inlet and outlet). A flexible bellows section is incorporated to isolate the stationary cryostat from the feedthrough port which moves $18 \mathrm{~mm}$ diag a ally due to thermal expansion of the DIII-D vacuum vessel during baking. The cryostat is elt rtricisly isolated from the feedthrough port by a section in the transfer line which is made using cummercially available brazed ceramic isolators. The cryogenic electrical break has been hi-pot tested to $30 \mathrm{kV}$. 


\section{CRYOGENIC PROTOTYPE TESTING}

A prototype testing program was carried out to investigate the pump surface temperature as a function of flow geometry, applied heat load, helium mass flow rate, and outlet conditions. The goal of the testing program was to ensure that the pump designed would maintain allowable surface temperature throughout a tokamak discharge. The allowable surface temperatures to effectively pump hydrogen and deuterium are $4.6 \mathrm{~K}$ and $6.3 \mathrm{~K}$ respectively. The pump is envisioned to be used almost entirely with deuterium plasmas, but there may be some occasional hydrogen experiments. A combination of sieady state and pulsed heat loads are applied to the pump before and during each discharge (Fig. 3). These heat loads can be categorized as follows :

- Joule heating ( $I^{2} R$ heating) - - Because the pump forms an electrically continuous ring, current is induced in the pump due to changes in the tokamak magnetic field. The heating varies before and during the discharge. The calculated energy deposition is $220 \mathrm{~J}$.

- Particle load - Heating due to gas pumping and energetic neutral particles emanating from the plasma recycling site. This is calculated to be as high as $20 \mathrm{~W}$ during a $10 \mathrm{~s}$ tokamak discharge.

- $\quad$ Steady state - Heat load due to conduction and radiation heat transfer. This is calculated to be $10 \mathrm{~W}$.

The prototype pump tested was identical to the installed pump except that it was "U"-shaped instead of being ring shaped. Joule heating was applied to the pump by connecting a programmable power supply across the ends to simulate the design heat loads. A total of 15 low mass $(0.03 \mathrm{~g})$ silicon diode temperature sensors were bonded directly to the pump surface at various axial and circumferential positions. Flow meters were located at the pump inlet and outlet.

Two basic pump flow geometries were tested; (1) a hollow tube $(25 \mathrm{~mm}$ o.d. $\mathrm{x}$ $0.9 \mathrm{~mm}$ wall), and (2) the same outer tube with a concentric $19 \mathrm{~mm}$ diameter inner flow plug. The flow plug reduces the flow area by forcing the fluid to flow through the annulus

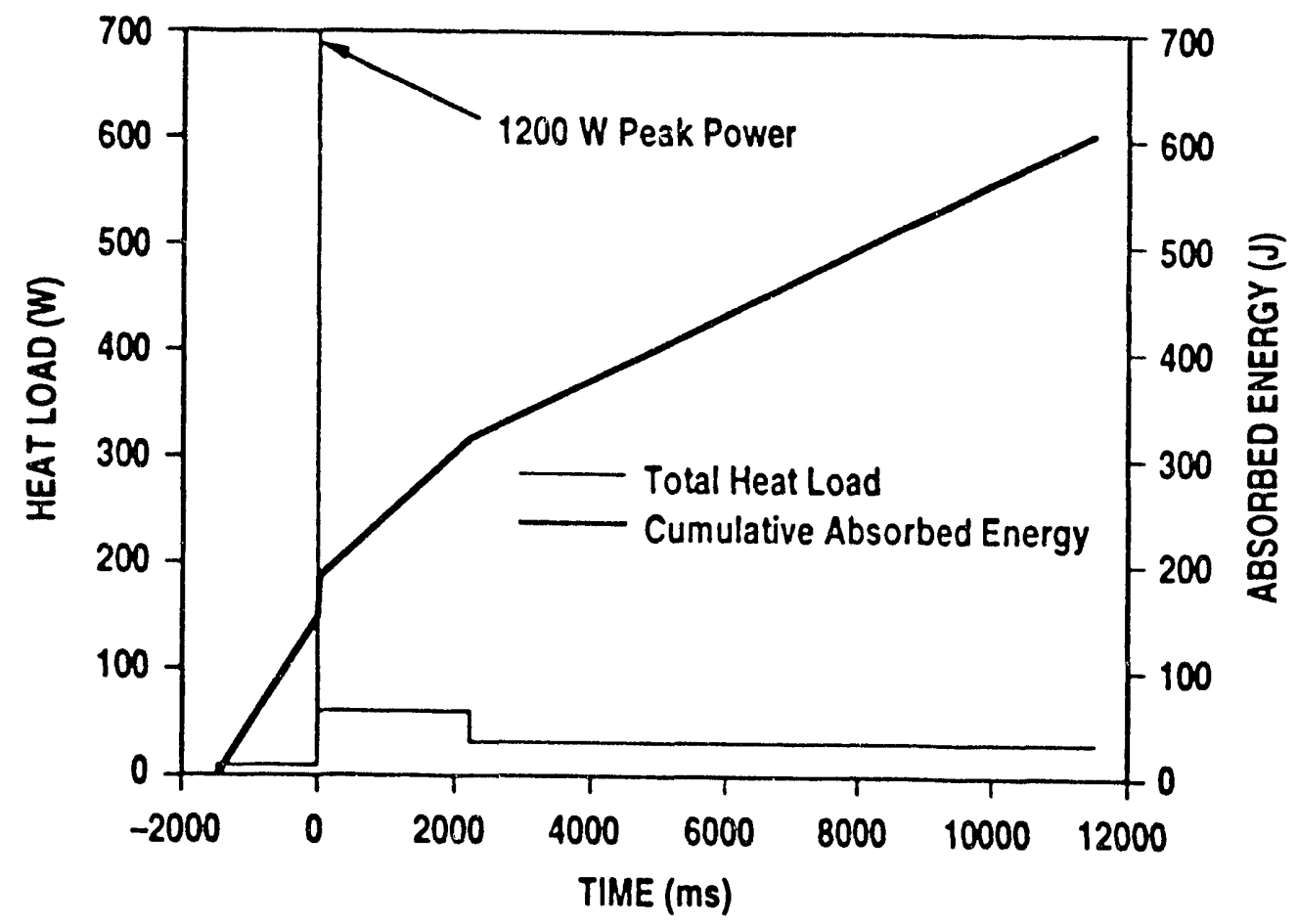

Figure 3. Calculated applied heat loading and cumulative energy applied to the pump vs. time. The plasma discharge begins at $0 \mathrm{~ms}$ and continues for up to $10,000 \mathrm{~ms}$. [Note the $1200 \mathrm{~W}$ power transient caused by plasma initiation.] 
thereby raising the flow velocity. Three different flow plugs were tested. The final flow plug geometry was developed during testing and then incorporated into the final pump design. The final design consists of a $19 \mathrm{~mm}$ o.d. by $0.25 \mathrm{~mm}$ wall perforated tube held centered inside of the $25 \mathrm{~mm}$ tube by spacers placed every $75 \mathrm{~mm}$ axially. The spacers block flow through the inner tube. The flow plug contains circumferential slits every $25 \mathrm{~mm}$ allowing it to fill with helium for increased heat capacity. These slits also provide the mechanical flexibility required for assembly into the final pump which has a radius of $1.6 \mathrm{~m}$. Also, by using thin wall Inconel 625 tubing, the toroidal electrical resistance is kept large and Joule heating due to induced currents is reduced as compared to a solid flow plug.

A radial array of 6 silicon diode surface temperature sensors were mounted $7.5 \mathrm{~m}$ downstream of the pump inlet (pump length $=10 \mathrm{~m}$ ). Figure 4 illustrates the benefit of the solid $19 \mathrm{~mm}$ diameter flow plug vs. no flow plug for two different mass flows. There is evidence of flow separation in the hollow tube pump. The surface temperature rise is substantially higher at the top of the tube than at the bottom. This effect becomes more pronounced as flow decreases. On the other hand, flow separation is minimal with the flow plug geometry.

Figure 5 shows test results using the $19 \mathrm{~mm}$ diameter solid flow plug at various massflows and powers. Note that the calculated maximum power applied to the pump during tokamak operations is expected to be $100 \mathrm{~W}$. In addition, the time of interest occurs during the first 10 seconds of the heat pulse corresponding to the tokamak discharge period. The heat loading used during testing consists of $10 \mathrm{~W}$ of steady state power to simulate radiation and conduction, plus a $30 \mathrm{~s}$ long heat pulse of 90 to $140 \mathrm{~W}$ to simulate Joule and particle heating (compare to Fig. 3). These results indicate temperatures will remain sufficiently low $(<6.3 \mathrm{~K})$ for deuterium pumping in all cases. However, the hydrogen pumping temperature limit of $4.6 \mathrm{~K}$ is exceeded at higher powers. Therefore, if the pump is used for hydrogen plasma operations in the future, the helium massflow will have to be increased to maintain temperature below $4.6 \mathrm{~K}$ with $100 \mathrm{~W}$ of heat input.

Note that temperature oscillations were observed at higher than design power loads. Flow oscillations in the inlet and outlet were also observed simultaneously during the testing. These temperature oscillations are caused by pressure and flow oscillations that occur when the expanding helium forces liquid out of the pump and into the warmer downstream piping.

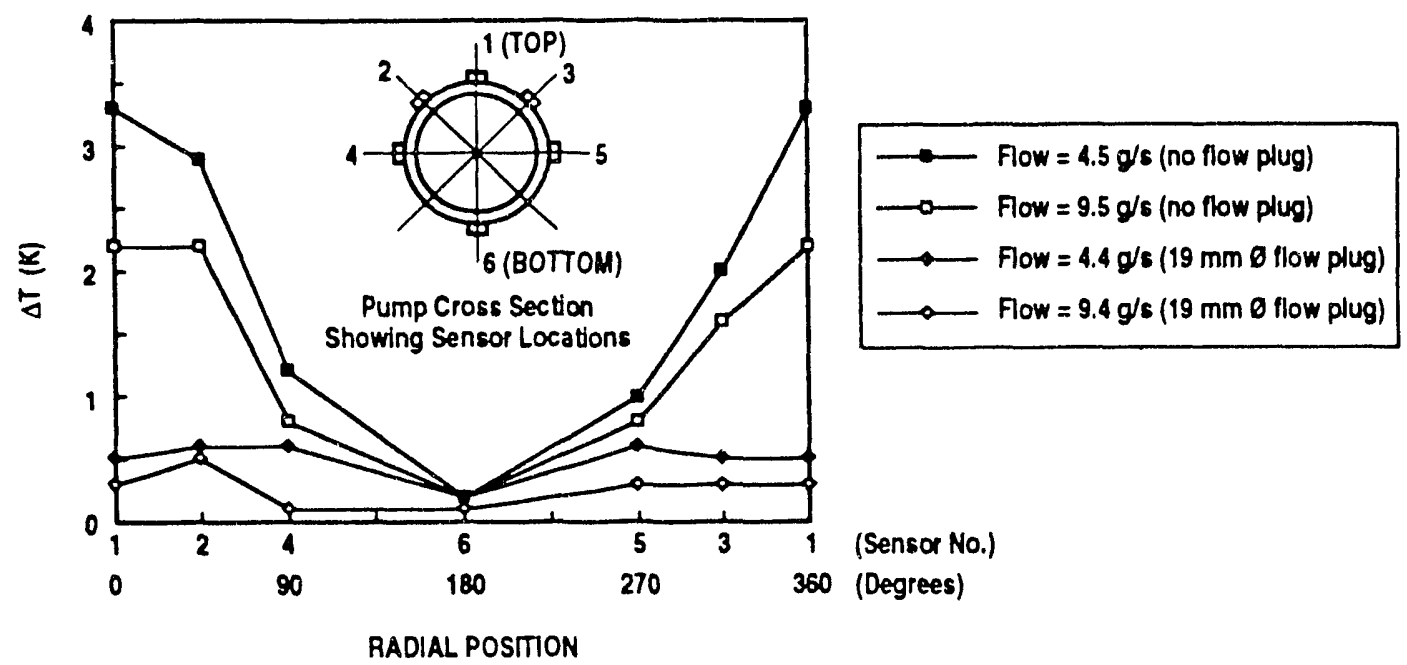

Figure 4. Radial surface temperature rise profiles of the prototype pump $10 \mathrm{~s}$ after the start of a 100 $W$ continuous heat pulse with and without a $19 \mathrm{~mm}$ diameter solid flow plug. All temperatures are measured at a cross section of the pump $7.5 \mathrm{~m}$ from the inlet. 


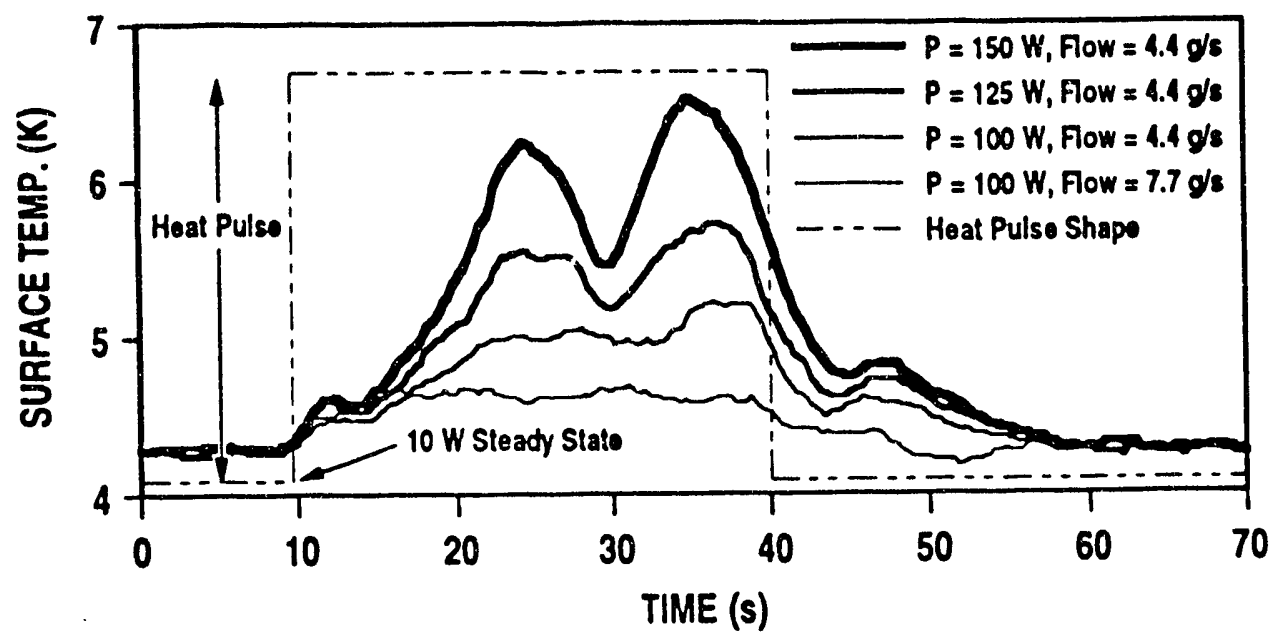

Figure 5. Surface temperature rise vs. time during heat pulse experiments with the $19 \mathrm{~mm}$ diameter solid flow plug. The temperatures are measured on top of the tube at a distance $7.5 \mathrm{~m}$ from the inlet of the $10 \mathrm{~m}$ long pump. The powers indicated in the legend are the total of $10 \mathrm{~W}$ of steady state heat load plus a heat pulse which simulates Joule and particle heat loads.

\section{OPERATION AND PERFORMANCE}

The advanced divertor cryopump is controlled by the DIII-D cryosystem programmable logic controller (PLC). The PLC is located in the cryogenics control room and is connected to the cryostat electronics rack via a fiber-optic link. Control must be done remotely because the cryostat and its electronics rack are located in the restricted tokamak area. The cryostat contains five proportional control valves, five precool solenoid valves, and temperature and pressure instrumentation. The cryo PLC is linked to the tokamak operations computer system so that operation and interlocking of the cryopump can be coordinated with tokamak operations. A personal computer based color graphics operator interface is used as an operations console for the cryopump. The operator controls the pump by selecting from a the list of modes shown in Table 1 .

During operations, tokamak discharges lasting up to 10 seconds typically take place every 10 minutes. Among other things, the time between discharges is used to condition the vacuum vessel walls by helium glow discharge cleaning for 8 minutes. The cryopump is regenerated simultaneously with the glow to desorb the deuterium pumped during the discharge. The helium pump warms at the beginning of the glow cis tharge because of the heat load caused by the $6.7 \times 10^{-2} \mathrm{mbar}$ ( $50 \mathrm{mTorr}$ ) gas fill pressure required for glow initiation. Once the glow is initiated, the helium fill pressure is lowered to about $2.7 \times$ $10^{-3} \mathrm{mbar}$ ( $2 \mathrm{mTorr}$ ) to sustain the glow discharge and recooling of the pump is begun. Due to its low thermal mass, re-cooling of the pump takes only 2 minutes. Bypass piping in the cryostat maintains flow through the heat exchanger and J-T valve to maintain stable operation while the helium flow to the pump is shut off for regeneration. Control of the cryostat during regeneration is done automatically by the PLC, and is coordinated with glow discharge cleaning if mode No. 6 (Table 1) is selected by the operator.

Since the installation of the cryopump in early 1993, the DIII-D tokamak operational cycle has been to operate five days a week for three straight weeks and then shut down for a two week maintenance period. Cryopumping is typically required on about half of the tokamak operations days. The nitrogen shield is kept cold during the entire three week operating period to avoid contaminating the inner walls of the tokamak with desorbed water vapor. The helium pump is cooled down only on those days which require cryopumping and allowed to warm up at the end of the day. Table 1 shows the cooldown times required starting from completely warm conditions. 
Table 1. Automatic operation modes of the advanced divertor cryosystem. Once selected by the operator, these modes are executed by PLC control.

\begin{tabular}{|c|c|c|c|}
\hline No. & Mode & $\begin{array}{l}\text { Duration* } \\
\text { (minutes) }\end{array}$ & Comments \\
\hline 1 & Precool LN 2 line to cryostat & 80 & Outer pass of Kabelmetal line \\
\hline 2 & Cooldown pump nitrogen shield & 30 & Slowly to minimize thermal stress \\
\hline 3 & $\begin{array}{l}\text { Precool J-T and LHe lines to } \\
\text { cryostat }\end{array}$ & 90 & $\begin{array}{l}\text { Inner passes (2) of Kabeliıetal } \\
\text { line }\end{array}$ \\
\hline 4 & Cooldown LHe pump & 30 & Slowly to minimize thermal stress \\
\hline 5 & Cooldown cryostat heat exchanger & 15 & \\
\hline 6 & Auto regeneration of LHe pump & 2 & $\begin{array}{l}\text { Regenerates between each } \\
\text { discharge }\end{array}$ \\
\hline 7 & Shutdown entire LHe flow circuit & 0.1 & Done at end of each operating day \\
\hline 8 & Shutdown entire $\mathrm{LN}_{2}$ flow circuit & 0.1 & $\begin{array}{l}\text { Done only at end of } 3 \text { week oper. } \\
\text { period }\end{array}$ \\
\hline 9 & Emergency shutdown & 0.1 & Safely isolates system if required \\
\hline
\end{tabular}

${ }^{*}$ Times listed were observed for cooldown from fully warm conditions.

Performance of the advanced divertor cryosystem and the overall DIII-D cryosystem have been quite stable and no two phase flow instabilities have been observed. Reliability of the cryopump is high and there have been no mechanical failures to date. The measured steady state LHe massflow is $4.9 \mathrm{~g} / \mathrm{s}$ while the J-T flow is $4.1 \mathrm{~g} / \mathrm{s}$. Therefore, the liquefaction load on the DIII-D cryosystem is $0.8 \mathrm{~g} / \mathrm{s}$. The refrigeration load has not been measured. The design values of liquefaction and refrigeration were $0.6 \mathrm{~g} / \mathrm{s}$ and $17 \mathrm{~W}$ at $4.6 \mathrm{~K}$ respectively. The reason for the $0.2 \mathrm{~g} / \mathrm{s}$ difference between the design value and the measured value for liquefaction can not be determined with the existing instrumentation.

Table 2 summarizes pumping speed measurements for the installed pump. These measurements were made by puffing gas into the tokamak at a known flowrate while measuring the pressures in the main vacuum chamber and within the pumping plenum. Gas puff lengths were 8 to $10 \mathrm{~s}$ long and steady state pressures were attained. 8 Deuterium pumping speeds were measured with heat loads of up to $300 \mathrm{~W}$. Deuterium pumping speed was found to be independent of heat load up to this power level. Hydrogen pumping speed measurements were done without applied heat loading.

Table 2. Pumping speed measurements of the installed pump on DIII-D. The helium massflow is $5 \mathrm{~g} / \mathrm{s}$.

\begin{tabular}{ccc}
\hline Gas & $\begin{array}{c}\text { Pressure } \\
\text { (millitorn) }\end{array}$ & $\begin{array}{c}\text { Pumping Speed } \\
(\mathrm{L} / \mathrm{s})\end{array}$ \\
\hline Hydrogen & 0.5 & 35,500 \\
& 4.0 & 43,500 \\
Deuterium & 0.5 & 24,500 \\
& 4.0 & 38,500 \\
\hline
\end{tabular}




\section{CONCLUSIONS}

The ADP cryopump has been operational since February 1993. Since that time it has been used Luring deuterium plasma operations and has proven to be a useful tool for controlling plasma density. Results from tokamak operations show that the deuterium pumping speed remains sufficiently high to maintain pumping throughout the discharge period. ${ }^{9}$ Operation is stable from a cryogenic standpoint and the pump does not slow down the discharge repetition rate even though it is regenerated between each tokamak discharge. The automatic operation of the pump will continue to be refined and improved as more operational experience is gained.

\section{ACKNOWLEDGMENTS}

The authors wish to express their gratitude to D. Cummings. E. Gonzales, J. Harris, A. Lucero, D. Morris, E. Taylor, R. Williams, and other technicians at General Atomics who so skillfully built this system.

This work was sponsored by the the U.S. Department of Energy under contract Nos. DE-AC03-89ER51114 and DE-AC05-84OR21400.

\section{REFERENCES}

1. M.A. Mahdavi, "The DIII-D collaborative advanced divertor program," General Atomics Report GA-A 19547 (February 1989).

2. J.P. Smith, C.B. Baxi, E.E. Reis, and D.L. Sevier, "A cryocondensation pump for the DIII-D advanced divertor program," in Proc. of the 10th Topical Meeting on the Technology of Fusion Energy, June 7-11, 1992, Boston, Massachusetts.

3. R.P. Reed and A.F. Clark. "Materials at low temperatures," American Society for Metals, Metals Park, Ohio (1983).

4. E.E. Reis, I. Almajan, C.B. Baxi, et al., "Design and analysis of the cryopump for the DIII-D advanced divertor," in Proc. of the 17th Symposium on Fusion Technology, Rome, Italy, September 14-18, 1992.

5. K.M. Schaubel, G.J. Laughon, G.L. Campbell, et al., "The DIII-D cryogenic system upgrade," to be published in Proc. of the 15th Symposium on Fusion Engineering," Hyannis, Massachusetts, October 11-15, 1993.

6. A.R. Langhorn, "The Doublet III neutral beam injector cryosystem," Advances in Cryogenic Engineering (Plenum, New York, 1983), Vol. 29.

7. H. Blessing, H. Laeger, Ph. Lebum, et al., "High performance flexible cryogenic helium transfer lines," Advances in Cryogenic Engineering (Plenum, New York, 198!), Vol. 27.

8. M.M. Menon, C.B. Baxi, G.L. Campbell, et al., "Performance characteristics of the DIII-D advanced divertor cryopump," to be published in Proc. of the 15th Symposium on Fusion Engineering," Hyannis, Massachusetts, October 11-15, 1993.

9. M.A. Mahdavi, et al. "Active density control in DIII-D H-mode plasmas," to be published in the Proc. of the 20th European Physical Society Conf. on Controlled Fusion and Plasma Physics, July 26-30, 1993, Lisboa, Portugal. 

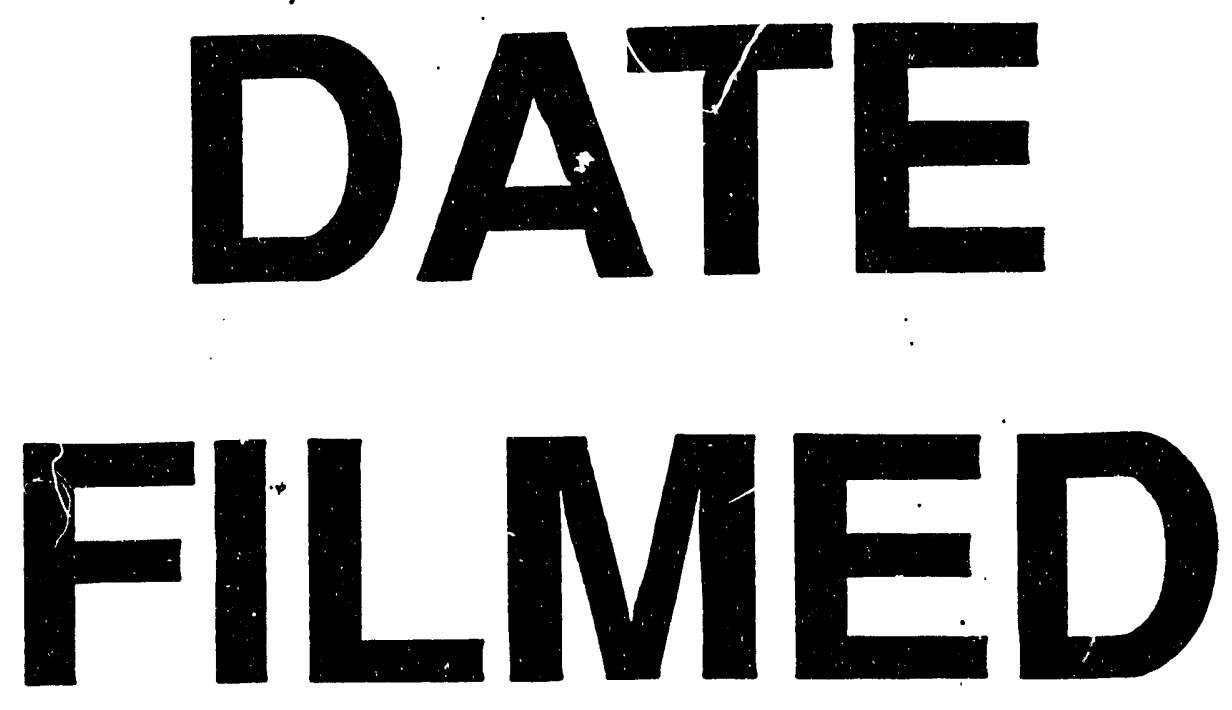

$12 / 16 / 93$
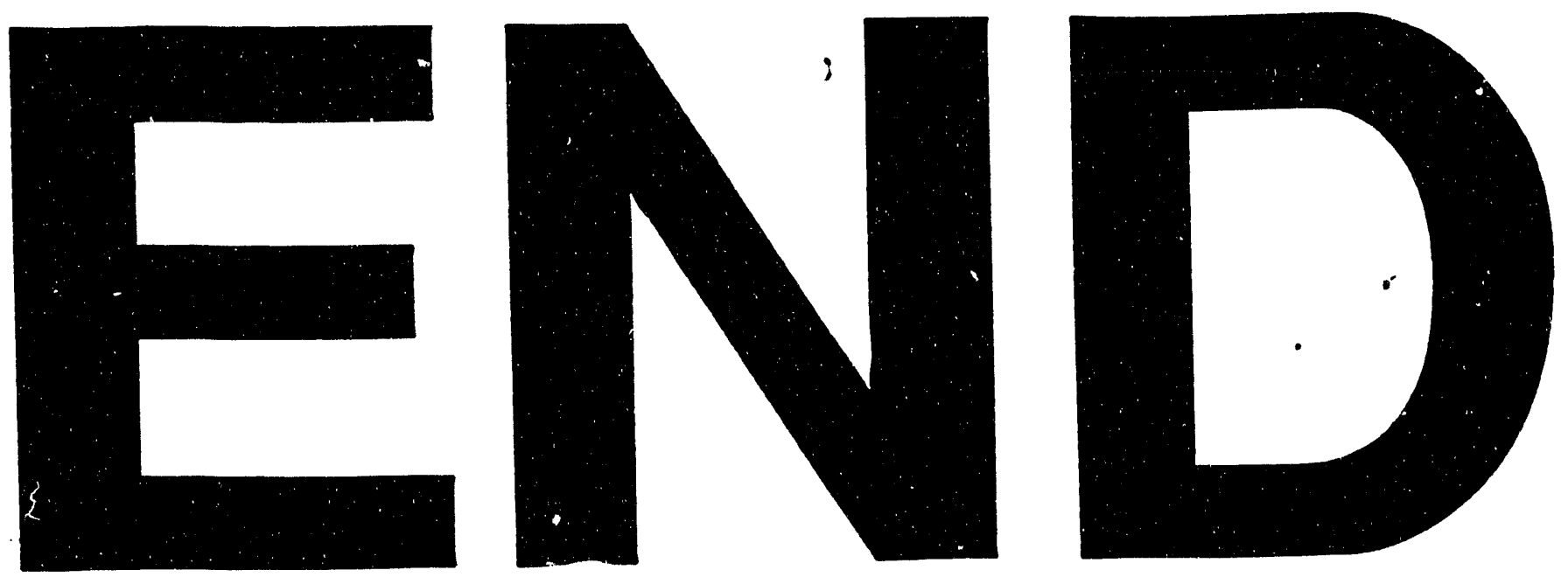
